\title{
The moral status of the near-term fetus
}

\author{
Carson Strong and Garland Anderson University of Tennessee, Memphis
}

In an earlier article, we discussed the difficult issue of balancing maternal and fetal interests in obstetric decision-making (1). We gave special attention to fetuses weighing more than 1000 grams (corresponding to approximately the third trimester) since we were discussing the issue of choosing a delivery method for premature fetuses in breech presentation, and since fetal risks during delivery have been documented to a greater degree for this group, compared to smaller fetuses. We argued, not that fetuses in this weight range are persons, but that they should be regarded as having the same moral status as persons. Our reasoning was essentially this: newborn infants are and should be regarded as having the same moral status as persons; moreover, there is no morally relevant difference between infants and fetuses in the weight range in question.

In a companion editorial Dr Raanan Gillon challenged our view and offered an alternative (2). He suggested that fetuses have an attenuated moral status compared to persons - so attenuated that it is permissible to kill them when doing so benefits persons. For fetuses who will be allowed to develop into persons, however, it is not permissible to do things that will harm the persons they will become. If survival is likely, then the fetus should be regarded as having the same moral standing as a person. Thus, for the type of case we discussed, his view yields the same conclusions as ours, provided the pregnant woman does not seek the death of the fetus. The difficulty with our view, according to Dr Gillon, arises in cases in which not killing the fetus would seriously threaten the pregnant woman's life. Most would agree that if one must choose between mother and fetus, it is preferable to save the mother's life. Dr Gillon's view easily squares with such intuitions but our view, he claims, would not permit killing the fetus to save the mother.

In reply, there are several considerations that support our view. To begin, other moral intuitions about infants and fetuses near term are also relevant to this issue. Consider our pre-theoretical intuitions about the moral status of newborns. The attitude that

\section{Key words}

Fetus; reproductive ethics; labour and delivery; breech; caesarean section; maternal-fetal conflict. they are persons, or at least that they should be $\frac{\vec{c}}{\mathrm{~T}}$ regarded as having the same moral status as persons, is:widely encountered. This attitude is reflected in the law, which regards newborns as legal persons. Similar,응 but perhaps less strong, intuitions are held concerning fetuses near term. We suspect that most obstetricians, $\bar{z}$ for example, would consider fetuses near term to have a moral status that is close to, if not equal to, that of $\frac{\rho}{\mathcal{O}}$ newborns.

Although such intuitions are widespread, they are sometimes discounted on the grounds that they are not defensible. For example, some philosophers argue that one must be self-conscious to be a person, and that regarding infants as persons is therefore based on confusion. However, there are other grounds for $\frac{\alpha}{\Phi}$ ascribing to newborns the same moral status as $\cong$ persons. As we pointed out, it can be argued that the $\overrightarrow{\overrightarrow{0}}$ participation of newborns in a social matrix justifies ascribing to them the same moral status that persons have. Such ascription appears to be based both on concern for the interests of newborns and its symbolic value. Failure to ascribe a right to life to newborns $\Phi$ might undermine respect for the lives of persons 3 generally. Similarly, failure to take their needs seriously might subvert the interests of others who are $\frac{0}{3}$ vulnerable. Thus, our attitudes toward newborns appear to be, in part, not only a symbolic expression of $\frac{}{2}$ our respect for persons, but one that is perceived as $\frac{\vec{O}}{0}$ having important consequences for the well-being of persons. When a philosophical theory (for example, $N$ the theory that infants should not be regarded as $N$ having the same moral status as persons because they $\mathrm{N}$ are not self-conscious) conflicts with such widespread $\omega$ intuitions, we should carefully consider whether the theory is strong enough to override those intuitions (3). Assuming that the social role of newborns provides a plausible justification for ascribing to them the same? moral status as persons, we should not reject these widespread intuitions.

Furthermore, the social role in question develops $\frac{\stackrel{\rho}{\mathbb{D}}}{\mathrm{D}}$ over time, beginning prior to birth. We argued that a $\varrho$ matrix of social interactions between fetus and others is usually present well before parturition. Factors $\delta$ contributing to this social role include the psychological attachment of parents to the fetus, as well as advances in obstetric technology that permit $\stackrel{ }{\rightleftharpoons}$ 
monitoring of the health status of the fetus and treatment or early delivery when needed. Since birth does not constitute a sharp dividing line between those with and those without a social role, there does not appear to be a morally relevant difference between infants and fetuses of sufficient degree to justify the view that infants have moral standing while fetuses near term do not.

According to our view, the less the degree to which the fetus can be said to be part of a social matrix, the weaker is the argument for regarding her/him as having the same moral status as persons. Near the borderline of viability (currently around the end of the second trimester) the fetus might be regarded as part of a social network to a lesser degree than at term. If so, the degree of weight that should be given to the fetus's interests varies, being stronger at term but relatively weaker when viability is questionable.

The view Dr Gillon describes has implications at odds with the above considerations. It implies that killing a fetus near term is permissible if it produces a benefit, even a minor one, for persons. Thus it would seem to condone killing a near-term fetus because the mother decided that she does not want to have an offspring after all. According to widely-held moral intuitions, however, this would not be acceptable. Depending on when personhood is deemed to begin, this view might even tolerate killing infants for similar reasons.

In addition, it is not at all clear that our view has the unacceptable implications stated by $\mathrm{Dr}$ Gillon. Assuming that the fetus should be regarded as having the same moral status as persons, it does not seem to follow that it is never justifiable to kill the fetus. To see this, let us consider an argument based on self-defence. We begin with the uncontroversial premise that killing an attacker in self-defence is sometimes morally permissible. Why, then, should it not be permissible to kill a fetus when doing so is necessary to save the pregnant woman's life? Although there is an apparent disanalogy since the fetus lacks intent to harm the woman, one can respond with examples like the one given by Professor Jane English:

'Suppose a mad scientist, for instance, hypnotised innocent people to jump out of the bushes and attack innocent passers-by with knives. If you are so attacked, we agree you have a right to kill the attacker in selfdefence, if killing him is the only way to protect your life or to save yourself from serious injury. It does not seem to matter here that the attacker is not malicious but himself an innocent pawn, for your killing of him is not done in a spirit of retribution but only in selfdefence' (4).

Although the fetus's lack of intent (or agency) does not seem material (5), it might be argued that self-defence is itself irrelevant. Even if it justified killing of the fetus by the woman, it would not justify killing by a third party such as the physician. However, there is a reply to this objection as well:

'But suppose you are a frail senior citizen who wishes to avoid being knifed by one of these innocent hypnotics, so you have hired a bodyguard to accompany you. If you are attacked, it is clear we believe that the bodyguard, acting as your agent, has a right to kill the attacker to save you from a serious beating. Your rights of self-defence are transferred to your agent. I suggest that we should similarly view the doctor as the pregnant woman's agent in carrying out a defence she is physically incapable of accomplishing herself' (4).

Perhaps it will be asked why the physician should be the woman's agent rather than the fetus's. The answer, we suggest, is that normally there are closer ties between the physician and woman than between the physician and fetus (6). Since the agreement to provide care is made with the woman, the physician is directly her agent. Moreover, the fact of widespread moral intuitions favouring the woman's life suggests that normal expectations are that, in such rare and tragic circumstances, the physician will save the woman. Thus, although these matters usually are not explicitly discussed, it can be argued that it is implicit in the agreement between physician and pregnant woman that her life takes precedence. Even if the fetus is regarded as having the same status as persons, it is preferable for the physician to act as the woman's agent.

For these reasons, we believe that the view we put forward is defensible.

Carson Strong PhD is Associate Professor, Department of Human Values and Ethics, University of Tennessee, Memphis. Dr Garland Anderson is Chief of Maternalfetal Medicine, Department of Obstetrics and Gynecology, University of Tennessee, Memphis.

\section{References}

(1) Anderson G, Strong C. The premature breech: caesarean section or trial of labour? Fournal of medical ethics 1988; 14:18-24.

(2) Gillon R. Pregnancy, obstetrics, and the moral status of the fetus. Fournal of medical ethics $1988 ; 14: 3-4$.

(3) Lomasky L E. Being a person - does it matter? In: Feinberg J, ed. The problem of abortion. (2nd ed). Belmont: Wadsworth Publishing Co, 1984; 161-172.

(4) English J. Abortion and the concept of a person. Canadian journal of philosophy 1975; 5:233-243.

(5) Davis N. Abortion and self-defence. Philosophy and public affairs 1984; 13:175-207.

(6) Devine P E. The ethics of homicide. Ithaca: Cornell University Press, 1978: 153.

\section{Editor's reply}

There is of course an enormous literature on the moral status of the embryo/fetus/neonate which it would be inappropriate and indeed presumptuous to try to 